\title{
Shutdown dose rate neutronics experiment during high performances DD operations at JET
}

\section{JET Contributors}

Elsevier

2018

JET Contributors 2018 , Shutdown dose rate neutronics experiment during high performances DD operations at JET . in S Cho , M-Y Ahn , M Akiba , K Feng , A Ibarra , M Q Tran \& H Hashizume (eds), Proceedings of the 13th International Symposium on Fusion Nuclear Technology (ISFNT-13) . Fusion Engineering and Design , no. Part B, vol. 136 , Elsevier , Amsterdam , pp. 1545-1549, International Symposium on Fusion Nuclear Technology , Kyoto , Japan , 25/09/2017 . https://doi.org/10.1016/j.fusengdes.2018.05.053

http://hdl.handle.net/10138/326648

https://doi.org/10.1016/j.fusengdes.2018.05.053

submittedVersion

Downloaded from Helda, University of Helsinki institutional repository.

This is an electronic reprint of the original article.

This reprint may differ from the original in pagination and typographic detail.

Please cite the original version. 
WPJET3-CPR(17) 17285

R Villari et al.

\section{Shutdown Dose Rate neutronics experiment during high performances DD operations at JET}

Preprint of Paper to be submitted for publication in Proceeding of 13th International Symposium on Fusion Nuclear Technology (ISFNT)

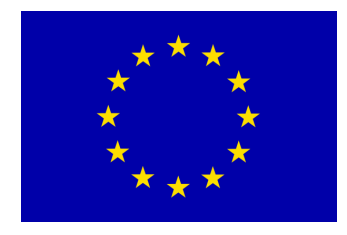

This work has been carried out within the framework of the EUROfusion Consortium and has received funding from the Euratom research and training programme 2014-2018 under grant agreement No 633053. The views and opinions expressed herein do not necessarily reflect those of the European Commission. 
This document is intended for publication in the open literature. It is made available on the clear understanding that it may not be further circulated and extracts or references may not be published prior to publication of the original when applicable, or without the consent of the Publications Officer, EUROfusion Programme Management Unit, Culham Science Centre, Abingdon, Oxon, OX14 3DB, UK or e-mail Publications.Officer@euro-fusion.org

Enquiries about Copyright and reproduction should be addressed to the Publications Officer, EUROfusion Programme Management Unit, Culham Science Centre, Abingdon, Oxon, OX14 3DB, UK or e-mail Publications.Officer@euro-fusion.org

The contents of this preprint and all other EUROfusion Preprints, Reports and Conference Papers are available to view online free at http://www.euro-fusionscipub.org. This site has full search facilities and e-mail alert options. In the JET specific papers the diagrams contained within the PDFs on this site are hyperlinked 


\section{Shutdown Dose Rate neutronics experiment during high performances DD operations at JET}

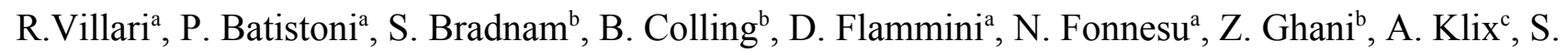
Loreti $^{\mathrm{a}}$, J. Naish ${ }^{\mathrm{b}}$, L. Packer ${ }^{\mathrm{b}}$, M. Pillon ${ }^{\mathrm{a}}$, S. Popovichev ${ }^{\mathrm{b}}$, I. E. Stamatelatos ${ }^{\mathrm{d}}$, T. Vasilopoulou ${ }^{\mathrm{d}}$ and JET Contributors*

EUROfusion Consortium, JET, Culham Science Centre, Abingdon, OX14 3DB, UK

${ }^{a}$ ENEA, Fusion and Technology for Nuclear Safety and Security, I- 00044 Frascati (Rome), Italy

${ }^{b}$ Culham Science Centre, Abingdon, Oxon, OX14 3DB, UK

${ }^{c}$ Karlsruhe Institute of Technology, 76344 Eggenstein-Leopoldshafen, Karlsruhe, Germany

${ }^{d}$ National Centre for Scientific Research Demokritos, Athens, Greece

*See the author list of "Overview of the JET results in support to ITER" by X. Litaudon et al. to be published in Nuclear Fusion Special issue: overview and summary reports from the 26th Fusion Energy Conference (Kyoto, Japan, 17-22 October 2016)

A novel Shutdown dose rate benchmark experiment has been performed at Joint European Torus (JET) machine during the last high performance Deuterium-Deuterium (DD) campaign in preparation of future high DeuteriumTritium experiment (DTE2). On-line continuous gamma dose rate measurements were performed for four months at two ITER relevant ex-vessel positions close to Radial Neutron Camera and on the top of ITER-like Antenna using high-sensitive ionization chambers. Decay gamma spectra at the shutdown were also collected using High Purity Germanium spectrometer to identify dominant radionuclides contributing to the dose. Neutron fluence measurements during operations were performed as well using activation foils assembly installed close to ionization chambers. The measurements are performed to validate shutdown dose rate tools used in ITER. This paper presents the experimental assembly and measurements analyses.

Keywords: JET, shutdown dose rate, benchmark, neutronics, decay gamma

author's email: Rosaria.villari@enea.it 


\section{Introduction}

In the frame of the EUROfusion Consortium, the Work Package DT Technology (WPJET3) was launched in 2014 to exploit the unique $14-\mathrm{MeV}$ neutron yields produced in DTE2 (up to $1.7 \times 10^{21}$ neutrons) at Joint European Torus (JET) and the use of tritium to validate codes, assumptions, models, procedures and data currently used for ITER [1]. The NEXP subproject is devoted to the preparation of neutronics benchmark experiments for validating the neutronics codes and tools for ITER nuclear analyses to predict the neutron flux along streaming paths and dose rates at the shutdown due to activated components $[2,3]$. In particular, the shutdown dose rate (SDR) assessments is a key issue for ITER design and the use of qualified and validated codes and nuclear data are essential to ensure the reliability of shutdown dose rate predictions. Complex threedimensional shutdown dose rate calculations require the use of computing tools coupling radiation transport and activation. During the last decades, Rigorous Two-Step (R2S) [4-6] and Direct One-Step (D1S) [7] tools based on MCNP Monte Carlo code [8] have been developed and extensively applied for ITER assessment. The prediction capabilities of these tools have been verified through several computational and experimental benchmarks and in particular, SDR benchmark experiments have been conducted at JET since 2005 [2, 911]. The results of the past benchmark experiments confirmed that the available calculation methodologies for shutdown dose rate assessments were in good agreement and capable of reproducing the measured quantities in the examined temporal range in a tokamak configuration within the experimental uncertainty margin. The major shortcomings of the previous benchmarking were the large experimental errors $(> \pm 30 \%)$, mainly due to calibration and positioning, and modelling uncertainties, mostly related to lack of complete information on trace impurities in chemical compositions.

The efforts recently carried-out in the new experiment during Deuterium-Deuterium (DD) campaign in preparation for future DTE2 are mainly devoted to reduce the experimental uncertainties and improve modelling accuracy. Furthermore dose rate measurements are now complemented with neutron fluence measurements during operation and gamma spectra at shutdown so as to identify the dominant radionuclides [2]. The experimental assembly and measurements analyses performed in the last 2016 DD benchmark are presented and discussed in this paper.

\section{Experimental assembly of DD experiment}

Shutdown dose rate, decay gamma spectra and neutron fluence measurements were performed during and at the end of the 2016 DD campaign.

Shutdown dose rate was measured using commercial spherical air-vented ionization chambers (PTW type TM32002, $\varnothing 140 \mathrm{~mm}$ ) procured by ENEA and KIT. These dosimeters were selected on the basis of the following requirements and operative conditions: low activation, large range of operation (from background to $30 \mathrm{mSv} / \mathrm{h}$, according to pre-analysis), high efficiency, long term stability, flat energy and dose response, isotropic angular response, radiation resistance (up to $10^{15} \mathrm{n} / \mathrm{cm}^{2}$ total fluence), compact dimensions, remote control and acquisition and compliancy with JET regulation [2]. Before the installation at JET, accurate calibration under $\mathrm{X}$ and gamma sources and preliminary irradiation tests under DT neutrons at the Frascati Neutron Generator (FNG) were performed [12].
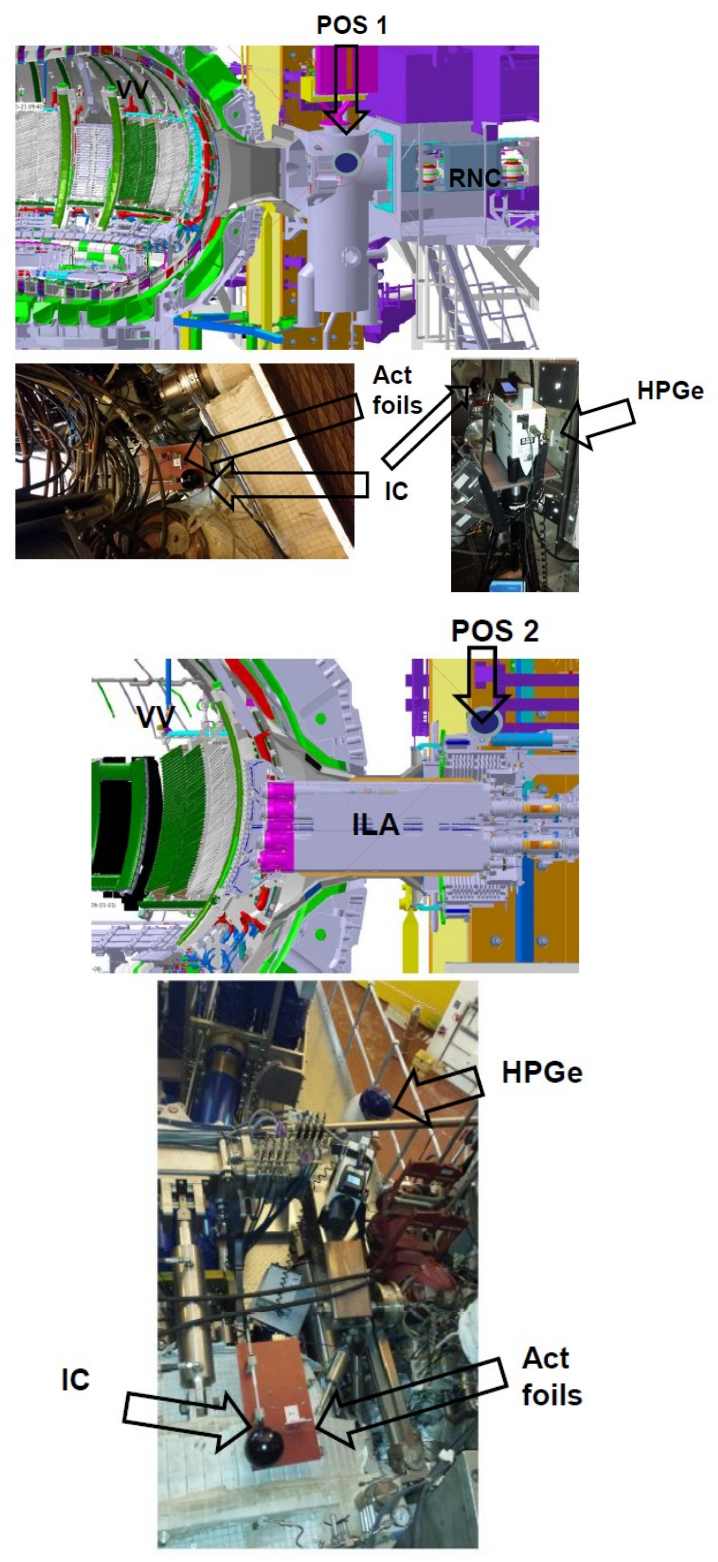

Fig.1 Experimental assembly for ex-vessel measurements of shutdown dose rate in positions \#1 (top) and \#2 (bottom).

For JET DD experiment, the ionization chambers (ICs) were installed in ITER-relevant locations on a low activation shelves in two ex-vessel positions close and on the top of two main horizontal ports of JET machine. One position is on the side port of Octant 1 (position \#1), the second position is on the top of ITER Like Antenna (ILA) in Octant 2 (position \#2). The positions are shown in Fig. 1. These were selected on the basis of space availability and JET constraints and to avoid interfering 
with other systems operations. It has been decided to locate the detectors close to the external mechanical structure. This strategy was adopted to reduce the modelling uncertainties related to the complexity and lack of complete information of the ex-vessel environment as well as to have sufficiently high dose rate level even during medium performances DD campaign. The position \#1 is the same as in JET 20122013 experiment [2]. The second position is on the top collar of ILA in Octant 2. The exact positioning of ICs has been verified through $3 \mathrm{D}$ scan. Low noise special cables (100 $\mathrm{m}$ long) connected the ICs to the electrometers located outside the torus hall. The software developed by ENEA to control both electrometers and ionization chambers was installed in a dedicated PC located in the cubicle. Operations of the detectors were managed from the JET control room via remote connection system and raw data were collected and saved [13]. Dose rate measurements started during the high performance phase of 2016 DD campaign and continued after the JET shutdown, occurred on $15^{\text {th }}$ November 2016 lasting more than four months. The results are provided in terms of air-kerma rate because, on the basis of calibration, the energy response of the ICs in terms of air-kerma is flat within $\pm 4.1 \%$ (at $95 \%$ of confidence level) [12].

Neutron fluence measurement were performed using two sets of cobalt, tantalum, silver and nickel activation foils (AF) in aluminium holders procured by the National Centre for Scientific Research Demokritos (NCSRD) and located close to the ICs in Octant 1 and Octant 2 (Fig. 1). The selection of the foils and of the assembly was defined on the basis of accurate preanalyses performed for the streaming experiment [14]. Taking into account the delay between the start of neutron irradiation and the activation foil measurements, only reactions with decay half-life of more than 60 days were used. Each foil holder was composed of three aluminium slabs of $100 \mathrm{~mm} \times 50 \mathrm{~mm} \times 1.5 \mathrm{~mm}$.

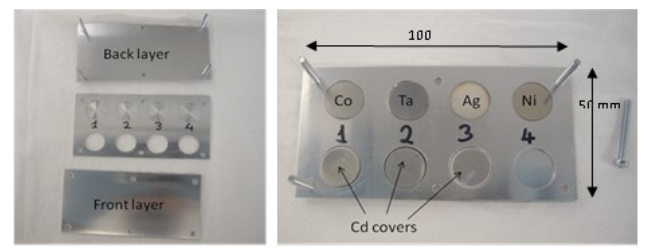

Fig. 2. Activation foil aluminum holder in position \#2 with $\mathrm{Co}, \mathrm{Ta}, \mathrm{Ag}$ and $\mathrm{Ni}$ bare foils and $\mathrm{Co}, \mathrm{Ta}$ and $\mathrm{Ag}$ foils covered with $\mathrm{Cd}$.

The holder in position \#1 contained $0.5 \mathrm{~mm}$ thick bare $\mathrm{Co}, \mathrm{Ag}, \mathrm{Ta}$ and $\mathrm{Ni}$ foils and a Cd-covered $\mathrm{Ag}$ foil and the holder in position \#2 contained both bare and Cd-covered Co, Ag and Ta foils and also a bare Ni foil (Fig. 2). The $0.5 \mathrm{~mm}$ thick Cd-cover was used to allow discrimination between thermal and epithermal neutrons. The selected reactions were ${ }^{59} \mathrm{Co}(\mathrm{n}, \gamma){ }^{60} \mathrm{Co},{ }^{181} \mathrm{Ta}(\mathrm{n}, \gamma)$ ${ }^{182} \mathrm{Ta},{ }^{109} \mathrm{Ag}(\mathrm{n}, \gamma){ }^{110 \mathrm{~m}} \mathrm{Ag}$ and ${ }^{58} \mathrm{Ni}(\mathrm{n}, \mathrm{p}){ }^{58} \mathrm{Co}$. The activation foils were exposed during the second part of the 2016 JET DD campaign from $28^{\text {th }}$ June 2016 to the shutdown (total JET neutron yield $1.22 \times 10^{19} \mathrm{n}$ ) [15].
High resolution decay gamma spectra were also acquired by CCFE with gamma spectrometer located behind the ICs as shown in figure 1. The selected detector is the Ortec Trans-SPEC-DX-100T portable High Purity Germanium (HPGe) with high resolution $(2.3 \mathrm{keV}$ at $1332 \mathrm{keV}$ ), large efficiency (relative efficiency $>40 \%)$, compact dimensions $\left(50 \times 50 \times 25 \mathrm{~cm}^{3}\right.$, weight $12 \mathrm{~kg}$ ) and Stirling-cycle cooler encapsulated in metal sealed cryostat. The spectra were acquired during surveys performed at the shutdown as soon as the access to JET torus hall was allowed (i.e. on $16^{\text {th }}$ November in position \#1 and on $17^{\text {th }}$ November 2016 in position \#2). Indeed, to avoid damage during neutron irradiation, it was unfeasible to hold the spectrometer installed in torus hall during JET operations.

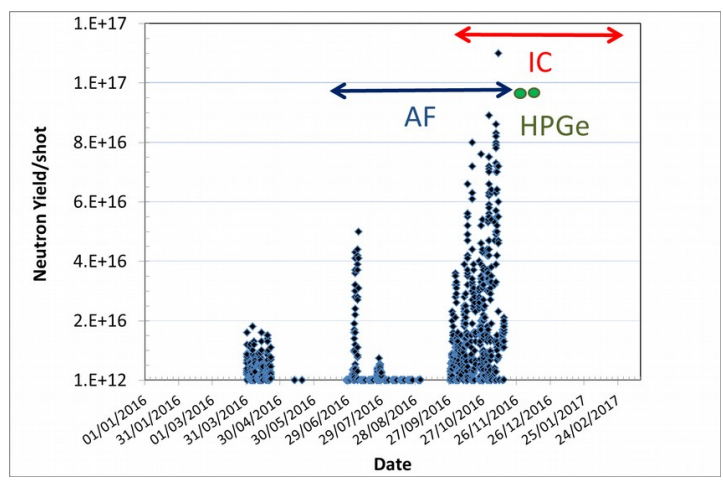

Fig 3. JET neutron irradiation history of 2016 DD

campaigns and dates of ICs, AF and HPGe measurements.

Figure 3 shows the irradiation history of 2016 DD campaign and the time schedule of the measurements with the different systems. The neutron yield per shot was measured by KN1 fission chamber neutron diagnostics. It's important to note that ICs measurements were performed during and at the end of the latest JET Deuterium campaign $\mathrm{C} 36 \mathrm{~b}$ which has achieved the highest performances in recent years with more than 400 shots, neutron yield per shot up to $1.1 \times 10^{17}$ and a total neutron yield higher than $9 \times 10^{18}$.

\section{Results of the measurements}

\subsection{Dose rate measurements with ICs}

The measurements with the ICs started on $18^{\text {th }}$ October 2016 , one week after the start of high performance DD campaign and continued until $24^{\text {th }}$ February 2017.

The IC signals (ionization current) were integrated over the settled integration time (i.e. $30 \mathrm{~s}$ during the campaign and $600 \mathrm{~s}$ at the shutdown) to obtain the collected charge and converted to air kerma using proper calibration factors. Correction factors which account for deviations from calibration conditions during measurements and influence quantities have been applied. The different sources of experimental uncertainties were carefully evaluated and quantified, providing an uncertainty of $\pm 3.8 \%$ (at $68 \%$ of confidence level), mainly due to the angular dependence of the dosimeter response to the incident radiation field. More details are in reference [13]. The air-kerma rates measured during the first 40 days are shown in figure 4 . The temporal correlation between the ICs signals and 
JET operations is shown in the bottom panel. Neutron yields are calculated as time integral of neutron emissivity measured by KN1 and are shown on the top. Ratio of signals (IC ENEA to IC KIT) is displayed in the middle plot of the same figure. The peaks in air-kerma rate results occur during neutron irradiation, but these data are useless because signals of both chambers tend to saturation current and moreover these are not calibrated in neutron field. Off-operations, the ICs showed a good temporal stability without drifts and significant perturbations due to harsh radiation conditions. Not even relevant effects due to the intense electric and magnetic fields have been observed. Furthermore, the lack of relevant signal degradation confirms that no damages were induced by neutrons. The dose rate measured with ENEA IC is higher than KIT IC as expected, because the KIT detector is located in a more shielded position in \#2 with respect to ENEA detector in \#1 [2]. Table 1 reports the air kerma rate from 2 hours (on $15^{\text {th }}$ November 2016) to 3.3 months (on $24^{\text {th }}$ February 2017) after shutdown. The absolute error includes the $\pm 3.8 \%$ uncertainty and the standard deviation of the average of the measurements over the integration time. The ratio between the ENEA (position \#1) and KIT (position \#2) values are also reported. The gamma decay in position $\# 2$ is faster than in position \#1 as predicted by preanalysis as well [2]. In the examined period, the dose rate decreases by a factor about 20 in position \#1 and by

a factor 200 in position \#2. It should be noted that due to an unexpected interruption in ICs acquisition system followed by several changes in torus hall environment due to neutron calibration campaign and maintenance interventions, for the scope of the benchmark, only the results up to 2 months after shutdown will be used.

Table 1. Air kerma rate measured with ICs at the JET shutdown. Ratio IC ENEA to IC KIT is also reported.

\begin{tabular}{|c|c|c|c|c|c|c|c|}
\hline & \multicolumn{3}{|c|}{ Position \#1 } & \multicolumn{3}{|c|}{ Position \#2 } & \multirow{2}{*}{$\begin{array}{l}\text { Ratio } \\
\# 1 / \# 2\end{array}$} \\
\hline $\begin{array}{l}\text { Time after } \\
\text { shutdown }\end{array}$ & $\mu \mathrm{Gy} / \mathrm{h}$ & & error & $\mu \mathrm{Gy} / \mathrm{h}$ & & error & \\
\hline $2 \mathrm{~h}$ & 22.53 & \pm & 0.88 & 6.08 & \pm & 0.25 & 3.7 \\
\hline $6 \mathrm{~h}$ & 10.30 & \pm & 0.42 & 2.80 & \pm & 0.13 & 3.7 \\
\hline $12 \mathrm{~h}$ & 5.03 & \pm & 0.29 & 1.31 & \pm & 0.10 & 3.8 \\
\hline 1 day & 3.52 & \pm & 0.21 & 0.73 & \pm & 0.07 & 4.8 \\
\hline 3 days & 2.95 & \pm & 0.11 & 0.40 & \pm & 0.02 & 7.4 \\
\hline 1 week & 2.79 & \pm & 0.11 & 0.31 & \pm & 0.03 & 9.0 \\
\hline 12 days & 2.63 & \pm & 0.10 & 0.28 & \pm & 0.02 & 9.4 \\
\hline 1 month & 2.19 & \pm & 0.09 & 0.20 & \pm & 0.02 & 11.0 \\
\hline 2 months & 1.68 & \pm & 0.07 & 0.11 & \pm & 0.01 & 15.0 \\
\hline 3.3 months* & 1.23 & \pm & 0.03 & 0.03 & \pm & 0.01 & 35.4 \\
\hline
\end{tabular}

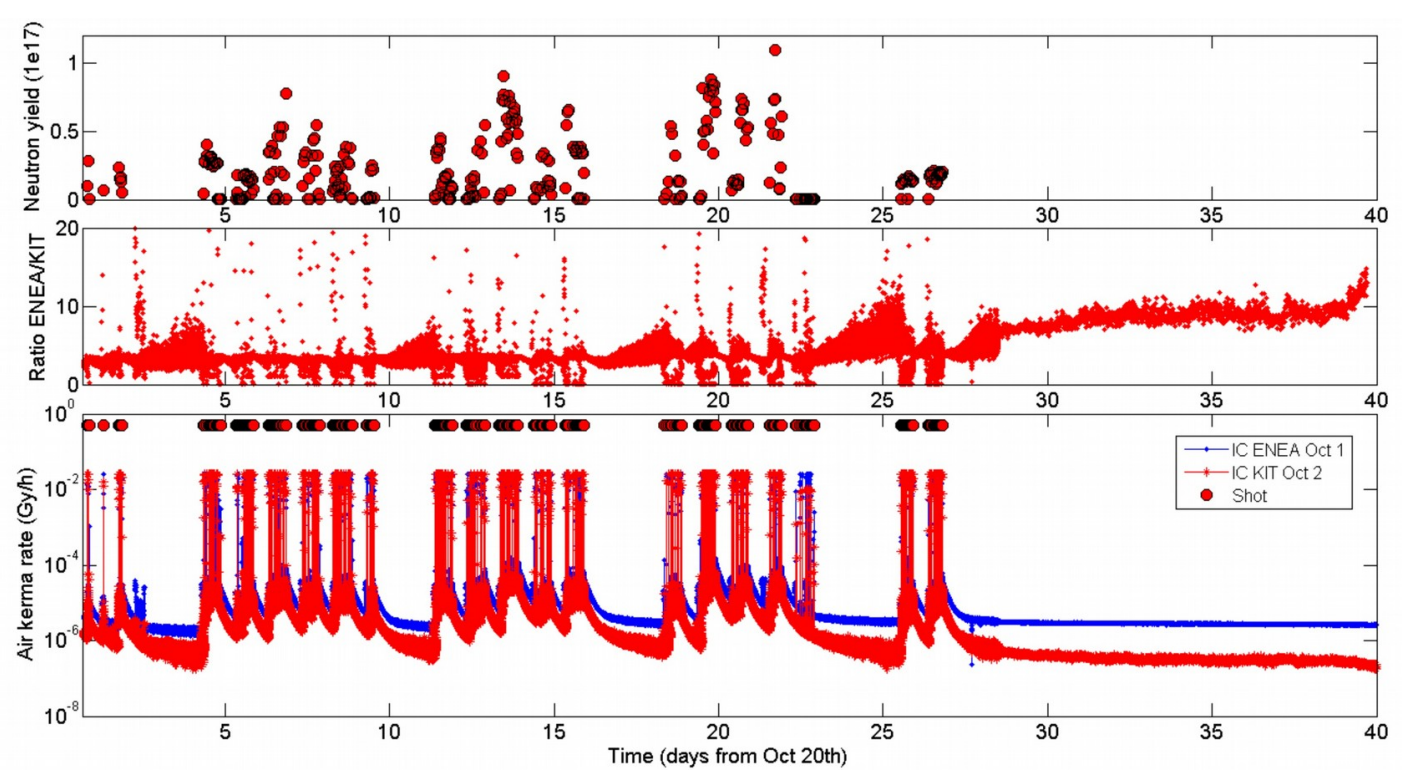

Fig. 4. Neutron yield per shot (top), ratio of ENEA to KIT ICs signals (middle) and air kerma rate measured with both ICs (bottom), dots on the top represent time of the JET shot, from $20^{\text {th }}$ October 2016 to $29^{\text {th }}$ November 2016.

\subsection{Neutron fluence measurements with activation foils}

The activation foils retrieved from JET torus hall were sent to NCRSD after clearance on $23^{\text {rd }}$ December 2016. Gamma-ray measurements were performed using a high-purity coaxial germanium semiconductor detector (GEM80) of $85 \%$ relative efficiency, energy resolution of $1.67 \mathrm{keV}$ at the $1332 \mathrm{keV}$ and a peak-to-Compton ratio of $93: 1$. The detector was surrounded by $5 \mathrm{~cm} \mathrm{lead}$ shielding for background radiation reduction. The acquired spectra were analyzed using the GammaVision software. The measured activities at the end of irradiation are reported in table 2 [14]. Higher activities are obtained in position \#1 than in position $\# 2$ as expected. The uncertainties include counting statistics, detector efficiency, gamma self-shielding and isotope half-life uncertainties. It should be noted that due to the 
low counting, the results in Cd-covered foils are within the error (about 10-14\%), so information on thermal component cannot be achieved.

Table 2. Activity and estimated neutron fluence in position 1 and 2 in the activated foils.

\begin{tabular}{lcccc}
\hline \multirow{2}{*}{ Foil } & \multicolumn{2}{c}{$\begin{array}{c}\text { Activity }(\mathrm{Bq})(\% \\
\text { rel.error })\end{array}$} & $\begin{array}{c}\text { Estimated neutron fluence } \\
\left(\mathrm{n} / \mathrm{cm}^{2}\right)\end{array}$ \\
\cline { 2 - 5 } & Bare foil & Cd-cov. foil & Bare foil & Cd-cov. foil \\
\hline \multicolumn{5}{c}{ Position \#1 } \\
\hline Co & $57.6(10)$ & - & $2.20 \times 10^{12}(10)$ & - \\
Ta & $1943(10)$ & - & $1.64 \times 10^{12}(10)$ & - \\
Ag & $25.5(10)$ & $25.1(10)$ & $1.56 \times 10^{12}(14)$ & $1.57 \times 10^{12}(14)$ \\
Ni8.5 (10) & - & $5.22 \times 10^{11}(11)$ & - \\
\hline \multicolumn{5}{c}{ Position \#2 } \\
\hline Co & $7.82(10)$ & $8.09(10.1)$ & $2.98 \times 10^{11}(10) 3.23 \times 10^{11}(10)$ \\
Ta & $399(10)$ & $357(10)$ & $3.37 \times 10^{11}(10)$ & $3.02 \times 10^{11}(10)$ \\
Ag & $5.30(10)$ & $4.29(10)$ & $3.24 \times 10^{11}(14)$ & $2.68 \times 10^{11}(14)$ \\
Ni & $0.095(14)$ & - & $5.81 \times 10^{9}(15)$
\end{tabular}

The preliminary results of the neutron fluence are also shown in table 2. A good agreement is observed between the neutron fluence results of tantalum and silver foils. Some discrepancies are observed in the case of the cobalt foil, which need to be further investigated. For $\mathrm{Co}$, Ta and $\mathrm{Ag}$ foils the estimated neutron fluence in position \#1 was found to be approximately a factor 5 to 7 higher than the fluence in position \#2. This finding is in agreement with the predictions and consistent with ICs measurements. A lower fluence is obtained by nickel foil as compared to the tantalum and silver values, because the result is mainly related to the fast component of the neutron spectrum $((\mathrm{n}, \mathrm{p})$ reaction). These preliminary results of neutron fluence have been obtained using a calculated neutron spectrum in Octant 1 close to activation foils position. It should be noted that the same neutron spectrum has been also used for deriving the fluence in position \#2. Using this approach, the estimated neutron fluence depends on the MCNP simulation and it is also affected by energy spectral shape. Proper calibration factor will be derived from dedicated irradiation campaign of the same foils assembly performed at the FNG and the neutron fluence will be re-assessed using independent calibration.

\subsection{Decay gamma spectra with portable HPGe}

Decay gamma spectra were acquired in position \#1 and \#2 at one day and two days after JET shutdown, respectively with portable HPGe gamma spectrometer by CCFE [16]. Time dependent spectral data were collected through the time intervals of 10 minutes through inbuilt digital signal processing incorporated into Trans-SPEC interfaced with MAESTRO software.
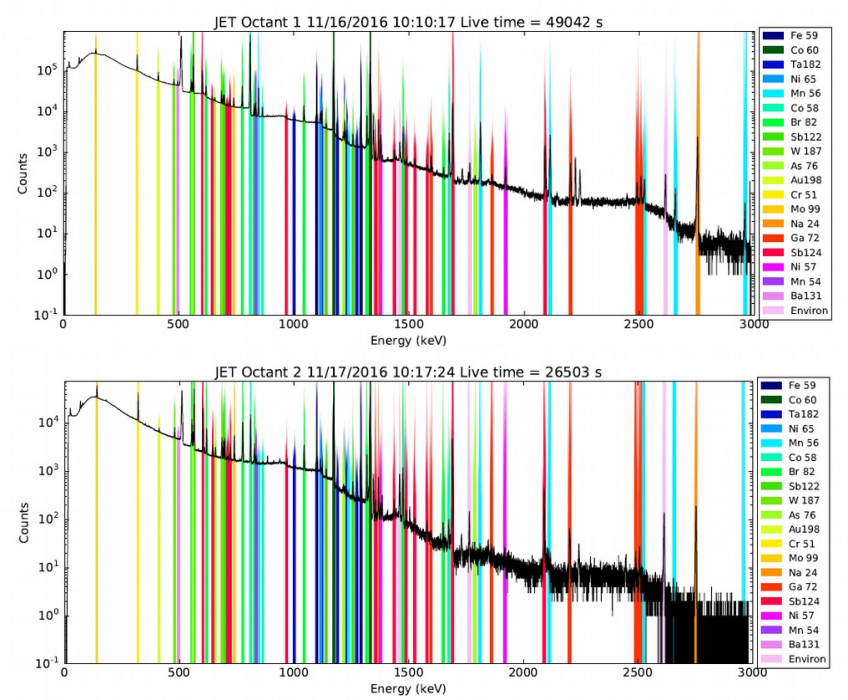

Fig. 5. Decay gamma spectra in position \#1 (top) acquired on $16^{\text {th }}$ November 2016 and in position \#2 (bottom) acquired on $17^{\text {th }}$ November 2016

Time dependent energy calibration based on gain shift corrections and an energy recalibration were performed at each time bin. Nuclide identification on recalibrated data was performed using database in MAESTRO software package. All gamma emitting nuclides identified in the full gamma spectra are shown in Fig. 5. Many radionuclides have been recognised and main contributions from vacuum vessel and mechanical structure activation products have been identified (i.e. ${ }^{60} \mathrm{Co},{ }^{58} \mathrm{Co},{ }^{56} \mathrm{Mn}$, etc...). Besides activation products, some of the more prominent environmental gamma lines have been identified in both positions as ${ }^{40} \mathrm{~K},{ }^{214} \mathrm{Bi}$ and ${ }^{208} \mathrm{Tl}$. Nearly all lines are activation products except 511 $\mathrm{keV}$ line due $\mathrm{e}^{+}-\mathrm{e}^{-}$annihilation and another peak measured at $2222 \mathrm{keV}$ from a ${ }^{1} \mathrm{H}(\mathrm{n}, \gamma)^{2} \mathrm{H}$ reaction in position \#1 maybe due to the presence of an $\mathrm{AmBe}$ neutron source in this octant. One of the major difference observed between the two spectra is the relative intensity of the ${ }^{56} \mathrm{Mn}$ gamma lines, more intense in position \#1 because the data in position \#2 were acquired 24 hours later and this nuclide has a half-life of 2.5 hours. Quantitative data analyses on the acquired spectra are in progress.

\section{Conclusions and future work}

Several measurements were performed during and at the end of last DD campaign at JET. The efforts were mainly devoted to improve the reliability of the techniques and to reduce the experimental errors as well as to optimize the assembly and mitigate risks for the future DTE2 experiment. Accurate MCNP modeling of JET Octant 1 and Octant 2 components and of the experimental assembly is in progress and the results of the calculations performed with R2S and D1S codes will be compared with the measurements. The improved accuracy of the experimental data can provide further confidence in the prediction capabilities of the computational tools for application to ITER and future power reactors. 
This work has been carried out within the framework of the EUROfusion Consortium and has received funding from the EURATOM research and training programme 2014-2018 under grant agreement No 633053. The views and opinions expressed herein do not necessarily reflect those of the European Commission.

\section{References}

[1] P. Batistoni et al., Technological exploitation of Deuterium-Tritium operations at JET in support of ITER design, operation and safety, Fusion Eng. Des., 109-111 (2016) 278-285

[2] R. Villari et. al., Neutronics experiments and analyses in preparation of DT operations at JET", Fusion Eng. Des., 109, (2016) 895-905

[3] R. Villari et al., ITER oriented neutronics benchmark experiments on neutron streaming and shutdown dose rate at JET, Fusion Eng. Des. (2017), http://dx.doi.org/10.1016/j.fusengdes.2017.03.037

[4] P. Pereslatvsev, et al., Novel approach for efficient calculations of mesh based Monte Carlo shutdown dose rates and related V\&V analyses on JET, Fusion Eng. Des. 89 (2014) 2083-2087.

[5] A. Davis and R. Pampin, Benchmarking the MCR2S system for high-resolution activation dose analysis in ITER, Fusion Eng. Des. 85 (2010) 87-92.

[6] JP Catalan, P. Sauvan and J. Sanz, Shutdown dose rate assessment for a DCLL blanket-based reactor: Application of the R2S-UNED approach, Fusion Eng. Des. 88 (2013) 2088-2091

[7] R. Villari, et al., Shutdown dose rate assessment with the Advanced D1S method: Development, applications and validation, Fusion Eng. Des. 80 (2014), 2083-2087

[8] X5 MONTE CARLO Team, "MCNP - a general Monte Carlo N-Particle transport code: version5 user's guide", LANL report LA-CP-03-0245, October 2005.

[9] R. Villari et. al., Validation of shutdown dose rate Monte Carlo calculations through a benchmark experiment at JET, Fusion Eng. Des. (2008) 83 1782-1787

[10] R. Villari et. al., Shutdown dose rate benchmark experiment at JET to validate the three-dimensional Advanced-D1S method, Fusion Eng. Des. 87 (2012) 1095-1100.

[11] R. Villari, et al. Overview of experimental benchmarking of shutdown dose rate calculations in fusion devices, ANS Transactions 109 (2013)1167-1170.

[12] N. Fonnesu et al., The preparation of the Shutdown Dose Rate experiment for the next JET Deuterium-Tritium campaign, Fusion Eng. Des. (2017), http://dx.doi.org/10.1016/j.fusengdes.2017.01.030.

[13] N. Fonnesu et al. , Shutdown Dose Rate Measurements after the 2016 Deuterium-Deuterium Campaign at JET, this conference

[14] I.E. Stamatelatos et al., Neutron streaming study along JET shielding penetration, Proc. of ICRS 13- RPSD 2016, 3-6 October 2016, Paris, France

[15] I.E. Stamatelatos et T. Vasilopoulou, Provision of activation foils and boxes for NEXP-SDR, WPJET3 Report D10 (2017)

[16] S. Bradnam et al., HPGe detector measurement in JET octants 1 and 2, WPJET3 Report D14 (2016) 